УСМАНОВА Заира Романовна - кандидат политических наук, доцент департамента политологии и массовых коммуникаций Финансового университета при Правительстве РФ (125993, Россия, 2. Москва, ГСП-3, Ленинградский пр-кт, 49; ZRUsmanova@fa.ru)

ЧЕРДАНЦЕВА Анжела Магомедовна - кандидат политических наук, научный сотрудник центра политологических исследований департамента политологии и массовых коммуникаций Финансового университета при Правительстве РФ (125993, Россия, г. Москва, ГСП-3, Ленинградский пр-кт, 49; cherdantseva.anzhela@yandex.ru)

\title{
СРАВНИТЕЛЬНЫЙ АНАЛИЗ ЭФФЕКТИВНОСТИ МЕР ПО ПРЕОДОЛЕНИЮ БЕДНОСТИ В ЗАРУБЕЖНЫХ СТРАНАХ
}

\begin{abstract}
Аннотация. В статье представлены результаты сравнительного исследования успешных мер по преодолению бедности и социального отчуждения в рамках социальной и экономической политики зарубежных стран. Авторы проводят аналитический обзор государственных программ и конкретных региональных мер, разработанных и применяемых в Европейском союзе и некоторых странах - участницах БРИКС, по преодолению материальной депривации и неравенства. Авторы приходят к мнению, что не существует универсальных методик по преодолению бедности ввиду многих экономических и неэкономических факторов, влияющих на экономическое развитие конкретных регионов. Целесообразнее разрабатывать более динамичные и кратковременные пакетные меры, способные эволюционировать параллельно с институциональными факторами.
\end{abstract}

Ключевые слова: бедность, социальное отчуждение, БРИКС, ЕС, социальная политика, экономическая политика

Oпыт стран Европейского союза. Проблема бедности является одной из ключевых повесток стратегии Европейского союза «Европа 2020». Согласно Лаакенской декларации, бедность вместе с отсталостью и региональными конфликтами подпитывает религиозный фанатизм, расизм, этнический национализм и терроризм [Четвериков].

Для замера риска бедности и социального отчуждения в ЕС был разработан показатель $A R O P E$, определяющий долю/численность населения, которое подвергается риску бедности или материальной депривации. В его основе лежат статистические исследования ЕС по доходам и условиям жизни $(E U-S I L C)$, собирающие данные по образованию, здравоохранению, доходам, жилищным условиям, трудоустройству, материальным лишениям [Измерение бедности... 2013]. При этом основанные на этих факторах замеры уровня бедности в странах ЕС значительно недооценивают региональные различия в бедности, которые зависят также и от того, где живет человек (эффект проживания).

В 2010 г. в целях преодоления последствий экономического кризиса была принята стратегия разумного, устойчивого и всеобъемлющего роста «Европа 2020». Среди целевых показателей стратегии «Европа 2020»-увеличение числа людей с законченным высшим образованием в возрасте 30-34 г. до 40\%; уменьшение числа людей, находящихся за чертой бедности, минимум на 20 млн; увеличение занятости населения в возрасте 20-64 лет минимум до 75\%1. Для достижения этих задач были разработаны следующие программы:

1) «Движение молодежи», которая включает увеличение привлекательности европейского образования, совершенствование сферы занятости молодых специалистов;

1 Europe 2020: A European strategy for smart, sustainable and inclusive growth. Brussels. 2010. P. 3. 
2) «План по развитию новых способностей и увеличению числа рабочих мест», который подразумевает совершенствование рынка труда, увеличение занятости, обучение новым знаниям для повышения конкурентоспособности в современных условиях, рост продуктивности труда и уменьшение безработицы;

3) «Европейская политика против бедности», которая предусматривает гарантии социального и территориального сотрудничества в борьбе с бедностью и социальным отчуждением, улучшение качества жизни, увеличение социальной активности в общественной жизни.

Эффективность данных программ можно оценить, обратившись к наиболее актуальным данным Евростата. Замеры уровня риска бедности и социального отчуждения производятся Евростатом как в общем для всех 28 стран ЕС (ЕС-28), так и для каждой страны отдельно. При этом Евростат замеряет уровень риска бедности разных социальных групп на основании индикаторов (возраст, гендерная принадлежность, социальное положение и т.п.). В 2010 г. в ЕС-28 уровень риска бедности и социального отчуждения для населения всех стран составил 23,8\%. В 2018 г. этот показатель составил 21,9\%1. Если обратиться к данным по конкретным странам, то интерес вызывает динамика снижения показателя уровня риска бедности в некоторых из них. Так, устойчивую положительную динамику показывает Чехия, где число бедных уменьшилось с 14,4\% в 2010 г. до 12,2\% в 2018 г. Это самый лучший показатель в ЕС-28. Самый худший показатель в 2018 г. $(41,1 \%)$ - у Северной Македонии, которая, тем не менее, показывает положительную динамику весь период реализации стратегии «Европа 2020»2.

Среди всех социальных групп наиболее незащищенной являются дети. В зоне риска бедности в современной Европе находятся более 20 млн детей: 25,6\% среди детей, растущих в многодетных семьях (2 взрослых с 3 и более детьми); $35,3 \%$ среди детей одиноких родителей ${ }^{3}$.

Стратегия «Европа 2020» предлагает для данных домохозяйств такие механизмы преодоления бедности, как регулирование политики занятости (поддержка родителей в поиске работы); система налоговых льгот; предоставление льготных или бесплатных ключевых услуг, таких как качественный уход за детьми; образование и защита прав детей. Последнее как основная цель ЕС 4 нашло свое отражение в Лиссабонском договоре 5 .

Для того чтобы сложилось более глубокое представление об эффективности конкретных мер по преодолению бедности и социального расслоения в мире, необходимо обратиться к опыту стран с экономикой, растущей высокими темпами, но при этом с населением, имеющим низкий уровень жизни по сравнению со странами ЕС. Для этого целесообразно обратиться к опыту некоторых стран - участниц БРИКС.

Среди зарубежных стран БРИКС успешным представляется опыт Китая,

1 Eurostat. People at risk of poverty or social exclusion by age and sex. Data online code: ilc_peps01. Доступ: https://ec.europa.eu/eurostat/web/main/home (проверено 21.03.2020).

2 Ibid.

3 Eurostat. At-risk-of-poverty rate by poverty threshold and household type - EU-SILC and ECHP surveys. Data online code: ilc_li03. Доступ: https://ec.europa.eu/eurostat/web/main/home (провереHо 21.03.2020).

4 MITTEILUNG DER KOMMISSION AN DAS EUROPÄISCHE PARLAMENT, DEN RAT, DEN EUROPÄISCHEN WIRTSCHAFTS- UND SOZIALAUSSCHUSS UND DEN AUSSCHUSS DER REGIONEN Europäische Plattform gegen Armut und soziale Ausgrenzung: Ein europäischer Rahmen für den sozialen und territorialen Zusammenhalt. Доступ: https://eur-lex.europa.eu/legalcontent/DE/ALL/?uri=CELEX:52010DC0758 (проверено 20.03.2020).

5 Лиссабонский договор, изменяющий Договор о Европейском союзе и Договор об учреждении Европейского сообщества (Лиссабон, 13 декабря 2007 г.) Доступ: https://eulaw.ru/treaties/ lisbon/ (проверено 20.03.2020). 
Индии и Бразилии по борьбе с бедностью и социальным неравенством. Так, большая часть наблюдаемого сокращения бедности происходит из-за непрерывного быстрого экономического роста в густонаселенных и изначально бедных развивающихся странах, таких как Китай и Индия, которые вместе с Бразилией вывели из бедности около 650 млн чел. [Radelet 2015]. Как отмечают отечественные исследователи В. Аникин и Н. Тихонова, бедность и неравенство в странах БРИКС существуют в кардинально разных социально-экономических условиях [Аникин, Тихонова 2016]. Исследователь М. Ревэллион провел сравнительный анализ сокращения бедности в Бразилии, Китае и Индии в период с 1981 по 2005 г. Указанный период отмечен им как наиболее успешный в плане сокращения бедности в Китае. В данный период в Китае наблюдался самый высокий темп роста ВВП на душу населения, близкий к $9 \%$ в год, за ним следуют Индия - около $4 \%$ и Бразилия - 0,8\% в год. Китай также показал лучшие результаты в сокращении бедности, которая снизилась с 84\% в 1981 г., когда началась политика «реформ и открытости», до 16\% в 2005 г. [Ravallion 2009].

Onыm Kuтая. В 2017 г. в Китае насчитывалось около 1386 млн чел. ${ }^{1}$, среди которых 9,7 млн являлись безработными. По данным на 13 декабря 2019 г., около 373 млн китайцев живут за чертой бедности на сумму не более 5,50 долларов США в день 2 .

Быстрое сокращение бедности в Китае обусловлено относительно низким неравенством в доступе к производительным факторам - земле и человеческому капиталу, которые помогли бедному населению активнее и успешнее реализовывать себя на рынке труда. В конце 1970-х гг. Китай провел серию «рыночных» реформ, будучи одним из первых аграрных реформаторов. Значительное сокращение бедности в Китае произошло в 1980-х гг., когда распались фермерские коллективы и произошло относительно справедливое распределение сельскохозяйственных угодий между индивидуальными фермерами. Так, рост сельского хозяйства играл важную роль в сокращении бедности в сельской местности до середины 1980-х гг. Далее тенденция роста перешла к городам и обрабатывающей промышленности, при этом доходы городских жителей росли быстреe [Radelet 2015]. В 1992 г. в Китае были внедрены новые методологии мониторинга бедности и преобразования результатов ее оценок. Это позволило разработать многоотраслевую модель сокращения бедности с упором на повышение мобильности рабочей силы в долгосрочной перспективе. Пилотными проектами стали: 1) проект по сокращению бедности на юго-западе (SWPRP) и 2) проект по сокращению бедности в горах Цинба. Эти меры позволили внедрить новую систему мониторинга бедности в Китае, которая в настоящее время принята на национальном уровне и реализуется во всех 592 бедных округах Китая. Проекты позволили обеспечить больший доступ населения к возможностям трудоустройства; улучшить работу служб здравоохранения и образования; расширить доступ к безопасной питьевой воде, сельским дорогам и другой базовой инфраструктуре; повысить продовольственную безопасность за счет улучшения земель и диверсификации производства более ценных культур и продуктов животноводства 3 .

Onыт Бразилии. В Бразилии в 2017 г. проживали около 208 млн чел., среди

\footnotetext{
${ }^{1}$ BRICS Joint Statistical Publication 2018 / Statistics South Africa. Pretoria: Statistics South Africa, 2018. Доступ: https://www.gks.ru/storage/mediabank/BRICS-2018.pdf (проверено 20.02.2020).

2 The World Bank in China. Доступ: https://www.worldbank.org/en/country/china/overview (проверено 20.02.2020).

3 Results Profile: China Poverty Reduction. Доступ: https://www.worldbank.org/en/news/ feature/2010/03/19/results-profile-china-poverty-reduction (проверено 20.03.2020).
} 
которых около 13 млн людей в возрасте от 16 лет и старше были безработными 1 . Бразилия оказалась успешнее в решении задачи по сокращению численности бедного населения, чем Индия, несмотря на более низкие темпы роста, снизив уровень бедности с $17 \%$ до $8 \%$. Ярким примером успешной программы, направленной на сокращение бедности и неравенства при прямом вмешательстве государства, является программа Бразилии по условному переводу денежных средств, направленных на помощь бедным, называемая Bolsa Familia («Семейный кошелек»)2 ${ }^{2}$. Данная программа, принятая в 2001 г., реализуется правительством Бразилии с 2003 г. и направлена на смягчение социальных последствий 1990-х гг. В Бразилии действовали также и другие социальные программы, направленные на борьбу с бедностью: Bolsa Escola («Школьный кошелек», 1995-2001 гг.), Fome Zero («Голода нет», 2001-2004 гг.) $)^{3}$.

Onыт Индии. Согласно данным Всемирного банка, в 2012 г. в Индии насчитывалось около 270 млн бедных людей. Среди стран БРИКС в Индии отмечается минимальный показатель экономического роста при максимальной доле сельского населения и населения, занятого в сельском хозяйстве, а также при максимальном естественном приросте населения (14,5\%). Сельская бедность в Индии составляет $80 \% 4$. Одним из индикаторов бедности в Индии является показатель недоедания у индийских детей, который в 5 раз выше, чем в Китае, и в 2 раза выше, чем в странах Африки к югу от Сахары. Основной причиной недоедания является отсутствие доступа к продовольствию. При этом в 2017 г. Индия снизила уровень бедности с $60 \%$ до 42\% [Radelet 2015]. Индийское правительство реорганизовало действующую программу комплексных услуг в области развития ребенка, уделив дополнительное внимание питанию беременных и кормящих женщин и детей в возрасте до 3 лет 5 .

Сравнительный анализ. В отличие от Китая, где на рост экономики влияние оказало развитие производственного и сельскохозяйственного секторов, на сокращение бедности в Индии и Бразилии гораздо большее воздействие оказал рост в секторе услуг. Тем не менее рост в Китае был гораздо более благоприятным, чем в Индии и Бразилии, главным образом благодаря высокому доступу к производственным факторам, росту производительности сельского хозяйства и расширению возможностей для занятости в несельскохозяйственном секторе. Первоначально высокий уровень неравенства в Бразилии являлся серьезным препятствием для сокращения масштабов нищеты. С другой стороны, у Бразилии было больше возможностей, чем у Китая, для реализации перераспределительной политики для решения проблемы бедности.

Необходимо отметить, что в целом на показатели снижения бедности в рассматриваемых странах влияние оказала общая макроэкономическая стабильность, в частности избежание инфляционных шоков.

Различия в показателях бедности во всех анализируемых странах объясняются, прежде всего, начальными условиями, характером экономического роста и тем, связан ли он с растущим неравенством, а также с политикой перераспре-

1 Poverty. Overview. Доступ: https://www.gks.ru/storage/mediabank/BRICS-2018.pdf (проверено 20.03.2020).

2 Bolsa Familia Program. Доступ: https://www.nasdaq.com/glossary/b/bolsa-familia-program (проверено 20.03.2020).

3 Bolsa Família 2019 Calendário de Pagamento. Доступ: https://bolsafamilia.net/ (проверено 20.03.2020).

4 India's Poverty Profile. Доступ: https://www.worldbank.org/en/news/infographic/2016/05/27/ india-s-poverty-profile (проверено 20.03.2020).

5 Помощь Индии в борьбе с неизменно высокими показателями недоедания. Доступ: https:// www.vsemirnyjbank.org/ru/news/feature/2013/05/13/helping-india-combat-persistently-high-ratesof-malnutrition (проверено 20.03.2020). 
деления, включая прямое вмешательство государства. В связи с этим представляется, что успешность мер по преодолению бедности связана и с тем, что социальная политика государства в интересах бедных должна быть сосредоточена на создании человеческого капитала из числа менее обеспеченных граждан, чтобы позволить им работать с более высокой производительностью [Ravallion 2009; Ravallion 2016]. Это говорит о том, что структурные изменения, связанные с процессом роста экономики с точки зрения создания рабочих мест и увеличения производительности труда, имеют первостепенное значение для борьбы с бедностью.

Таким образом, эффективность реализации программ преодоления бедности и социально-экономических проблем в каждом конкретном регионе мира имеет ряд особенностей.

Во-первых, в основе механизмов, тормозящих экономический рост и затрудняющих реализацию программ по преодолению бедности, лежат неэкономические факторы, в т.ч. ментальные и социокультурные механизмы, обусловливающие экономическое поведение хозяйствующих субъектов. Привыкшие к бедности слои сложно воспринимают инвестиции в активизацию их рационального экономического поведения, ожидая преимущественно социальных льгот и прямых денежных вливаний.

Во-вторых, специфика мер, применяемых в каждой конкретной стране, зависит от существующих социально-экономических условий. Страны, имеющие аграрный уклон, вынуждены сначала реализовывать программы для этого сектора экономики и только во вторую очередь развивать предпринимательство, производство и высокотехнологичные сферы.

B-третьих, отличия в цифрах, отражающих темпы снижения бедности в разных странах, зависят от конкретных диагностических процедур и систем мониторинга. В связи с тем, что указанные системы не унифицированы и приведение их к общему знаменателю не представляется целесообразным ввиду специфики исходных параметров, необходимо группировать страны и меры исходя из последних. Именно сходство исходных параметров бедности и факторов экономического поведения в конкретных странах (и даже регионах внутри стран) позволяет проводить оценку эффективности мер и делать прогнозы.

Статья подготовлена по результатам исследований, выполненных за счет средств Научного фонда по заданию Финуниверситета.

\section{Список литературы}

Аникин В., Тихонова Н. 2016. Бедность и неравенство в странах БРИКС: российская специфика. - Общество и экономика. № 1. С. 78-114.

Измерение бедности и социальной интеграции в ЕС: достижения и дальнейшее улучшение. Конференция европейских статистиков. Семинар «Перспективы измерения бедности». (Женева, 2-4 декабря 2013 г.) Доступ: https://www.unece. org/fileadmin/DAM/stats/documents/ece/ces/ge.15/2013/WP25_Eurostat_D_ Rus_Final.pdf (проверено 20.02.2020).

Четвериков А.О. Лаакенская декларация (Декларация Лаакена). Будущее Европейского союза (Лаакен, 15 декабря 2001 г.). Доступ: https://eulaw.ru/treaties/ laakenskaya-deklaratsiya-budushhee-evropejskogo-soyuza (проверено 20.03.2020).

Radelet S. 2015. The Great Surge: the Ascent of the Developing World. Simon \& Schuster Paperbacks. 354 p.

Ravallion M. 2009. A Comparative Perspective on Poverty Reduction in Brazil, China and India: Policy Research working paper No. WPS 5080. Washington, DC: World Bank. 
39 p. URL: http://documents.worldbank.org/curated/en/952341468218101551/pdf/ WPS5080.pdf (accessed 20.02.2020).

Ravallion M. 2016. The Economics of Poverty: History, Measurement, and Policy. Oxford University Press. 702 p.

USMANOVA Zaira Romanovna, Cand.Sci. (Pol. Sci.), Associate Professor of the Department of Political Science and Mass Communications, Financial University under the Government of the Russian Federation (49 Leningradsky Ave, GSP-3, Moscow, Russia, 125993; ZRUsmanova@fa.ru)

CHERDANTSEVA Anzhela Magomedovna, Cand.Sci. (Pol.Sci.), Researcher of the Center for Political Science Studies, Department of Political Science and Mass Communications, Financial University under the Government of the Russian Federation (49 Leningradsky Ave, GSP-3, Moscow, Russia, 125993; cherdantseva.anzhela@yandex.ru)

\title{
COMPARATIVE ANALYSIS OF THE EFFICIENCY OF MEASURES TO OVERCOME POVERTY IN FOREIGN COUNTRIES
}

\begin{abstract}
The article presents the results of a comparative study of successful measures to overcome poverty and social exclusion in the framework of the social and economic policies of foreign countries. The authors conduct an analytical review of government programs and practical regional measures developed and applied in the European Union and some BRICS member countries to overcome material deprivation and inequality. The authors mean there are not any universal methods exist to overcome poverty because of many economic and non-economic factors affecting the economic development of specific regions. It is advisable to develop more dynamic and short-term package measures, which can evolve in parallel with institutional factors.
\end{abstract}

Keywords: poverty, social exclusion, BRICS, EU, social policy, economic policy 